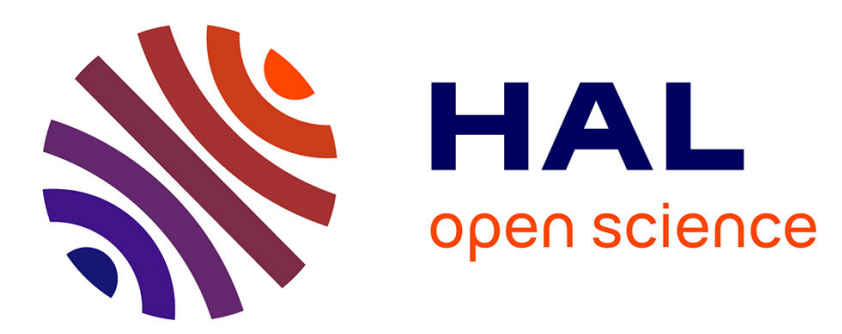

\title{
Laser induced damage of fused silica polished optics due to a droplet forming organic contaminant
}

Karell Bien-Aimé, Jérôme Neauport, Isabelle Tovena-Pecault, Evelyne Fargin, Christine Labrugère, Colette Belin, Michel Couzi

\section{- To cite this version:}

Karell Bien-Aimé, Jérôme Neauport, Isabelle Tovena-Pecault, Evelyne Fargin, Christine Labrugère, et al.. Laser induced damage of fused silica polished optics due to a droplet forming organic contaminant. Journal of Optics A: Pure and Applied Optics, 2009, 48 (12), pp.2228-2235. 10.1364/AO.48.002228 . cea-01217065

\section{HAL Id: cea-01217065 https://hal-cea.archives-ouvertes.fr/cea-01217065}

Submitted on 18 Oct 2015

HAL is a multi-disciplinary open access archive for the deposit and dissemination of scientific research documents, whether they are published or not. The documents may come from teaching and research institutions in France or abroad, or from public or private research centers.
L'archive ouverte pluridisciplinaire HAL, est destinée au dépôt et à la diffusion de documents scientifiques de niveau recherche, publiés ou non, émanant des établissements d'enseignement et de recherche français ou étrangers, des laboratoires publics ou privés. 


\title{
Laser induced damage of fused silica polished optics due to a droplet forming organic contaminant
}

\author{
Karell Bien-Aimé, ${ }^{1,2, \star}$ Jérome Néauport, ${ }^{1}$ Isabelle Tovena-Pecault, ${ }^{1}$ Evelyne Fargin, ${ }^{2}$ \\ Christine Labrugère, ${ }^{2}$ Colette Belin, ${ }^{3}$ and Michel Couzi ${ }^{3}$ \\ ${ }^{1}$ Commissariat à l'Energie Atomique/Centre d'Etudes Scientifiques et Techniques d'Aquitaine, \\ BP2, 33114 Le Barp, France \\ ${ }^{2}$ Institut de Chimie de la Matière Condensée de Bordeaux, Centre National de la Recherche Scientifique, \\ Université Bordeaux 1, 87 Avenue du Docteur Albert Schweitzer, 33608 Pessac cedex, France \\ ${ }^{3}$ Institut des Sciences Moleculaires (Unité Mixte de Recherche 5255), Université Bordeaux 1, \\ 351 Cours de la Libération, 33405 Talence cedex, France \\ ${ }^{\star}$ Corresponding author: karelle.bien-aime@cea.fr
}

Received 10 November 2008; revised 9 March 2009; accepted 25 March 2009; posted 26 March 2009 (Doc. ID 103804); published 14 April 2009

\begin{abstract}
We report on the effect of organic molecular contamination on single shot laser induced damage density at the wavelength of $351 \mathrm{~nm}$, with a $3 \mathrm{~ns}$ pulse length. Specific contamination experiments were made with dioctylphthalate (DOP) in liquid or gaseous phase, on the surface of fused silica polished samples, bare or solgel coated. Systematic laser induced damage was observed only in the case of liquid phase contamination. Different chemical and morphological characterization methods were used to identify and understand the damage process. We demonstrate that the contaminant morphology, rather than its physicochemical nature, can be responsible for the decrease of laser induced damage threshold of optics. (C) 2009 Optical Society of America
\end{abstract}

OCIS codes: $\quad 120.3940,140.3330,160.6030$.

\section{Introduction}

The French atomic energy agency, Commissariat à l'Energie Atomique (CEA), is currently building the MegaJoule Laser (LMJ) [1], a 240 beam laser fusion facility. This high power laser fusion facility, similar to the National Ignition Facility [2] in the United States, will deliver a total energy of $1.8 \mathrm{MJ}$ at a wavelength of $351 \mathrm{~nm}$. The Ligne d'Intégration Laser (LIL) [3], a prototype of the future LMJ, is intended to validate the technological choices made for the future LMJ. The LIL, which consists of eight individual beams, is our working environment. In this facility, laser beams are amplified by neodymium glass laser slabs at a wavelength of $1053 \mathrm{~nm}$. Each beam is then frequency converted to a wavelength

0003-6935/09/122228-08 $\$ 15.00 / 0$

(C) 2009 Optical Society of America of $351 \mathrm{~nm}$ in the frequency conversion system (FCS). Maximal fluences of $25 \mathrm{~J} / \mathrm{cm}^{2}$ are expected at $1053 \mathrm{~nm}$ and $14 \mathrm{~J} / \mathrm{cm}^{2}$ at $351 \mathrm{~nm}$ for a $3 \mathrm{~ns}$ pulse length. When submitted to such fluences at $351 \mathrm{~nm}$, fused silica optics used to convey the beam after frequency conversion can exhibit localized damage that dramatically limits the optics lifetime [4]. This damage can be intrinsic, as it can depend on the previous fabrication polishing process. In this paper, we focus on the effect of molecular contamination as an extrinsic cause to UV laser damage of fused silica optics. Various studies in microelectronic and spatial domains have shown that organic molecular contamination in a confined environment can be responsible for the degradation of optical performances. Reflective and transmissive losses as well as laser induced damage have been correlated to organic contamination level in many cases $[5,6]$. The studied wavelengths ranged from far ultraviolet to 
visible domains, and the incriminated molecules were aromatics, siloxane derivatives, and phthalates. Moreover, many studies with high repetition laser rates have demonstrated that chemical contamination can be responsible for laser induced damage. In most cases, laser damage was generated by a thermo mechanical rupture caused by absorption in a photo-deposited chemical pollution of aromatics, siloxanes, or phthalate molecules [7-11]. In these studies, the authors were interested in near IR or visible wavelengths, and the studied fluences were less than $1 \mathrm{~J} / \mathrm{cm}^{2}$. In our particular case, a fluence normal to the surface and higher than $10 \mathrm{~J} / \mathrm{cm}^{2}$ at a wavelength of $351 \mathrm{~nm}(3 \omega)$ for $3 \mathrm{~ns}$ pulse duration and a single shot/day frequency are considered. Consequently, the contaminant effects we see as well as the physical laser damage mechanism implied shall be different than seen under other conditions.

Our first step was to get a good knowledge of the organic contaminants present in our facility. Hence daily organic compound measurements have been taken during a few days in the FCS of the LIL facility. Samplings have been done using solid adsorbent cartridges. The adsorption tubes were placed inside an automated thermal desorption device and analyzed with a gas chromatograph coupled with a mass spectrometer (GC-MS). Aromatics, alkans, alcohol, ester, aldehyde, phthalates, and silicons were found [12]. Phthalate compounds have particularly drawn our attention, as they are condensable molecules commonly found on surfaces. Figure 1 presents daily measures of phthalates in the FCS environment. Important amounts of dioctylphthalate (DOP) were also noted. The major source of this molecule is the outgassing from materials present in the envir- onment of the LIL. As DOP is a plasticizer, many types of equipment can be responsible for its outgassing. According to GC-MS measurements, DOP has been found in substantial concentration compared to its vapor pressure since DOP partial pressure is on average $2,2.10^{-7}$ mbar, and bibliographic data give a DOP vapor pressure of about $4.10^{-7} \mathrm{mbar}$ [13]. This induces a possible condensation of DOP. Moreover, Pereira [14] established an important degradation of laser induced damage density of a $\mathrm{SiO}_{2} / \mathrm{HfO}_{2}$ dielectric mirror contaminated by microscopic droplets of DOP at $1064 \mathrm{~nm}$ in a single shot laser irradiation condition. Based on these considerations, we decided to study the effect of DOP contamination on laser induced damage of fused silica optics for single shot conditions similar to those of our LIL and LMJ facilities at $351 \mathrm{~nm}$.

Our experimental procedure is divided in different steps: surface sample cleaning, controlled contamination, morphological and chemical characterization of the deposit, laser irradiation of the substrates, and damage observation. For this study, we use $50 \mathrm{~mm}$ diameter, $5 \mathrm{~mm}$ thick plano-parallel samples made of Suprasil S312 synthetic fused silica from Heraeus. Samples are superpolished (surface roughness of a few angstroms) using colloidal silica as a polishing compound. An automated cleaning procedure in a spray system machine with RBS 50 soap is then used to clean the samples. Damage site density data confirmed that our samples were clean as, at this step, all bare samples exhibit the same laser induced damage density as typical clean LIL or LMJ optics, i.e., approximately 0.1 damage $/ \mathrm{cm}^{2}$ at $351 \mathrm{~nm}$, for $10 \mathrm{~J} / \mathrm{cm}^{2}$, and $3 \mathrm{~ns}$ pulse length. As DOP is known to be commonly found on surfaces, we are likely to

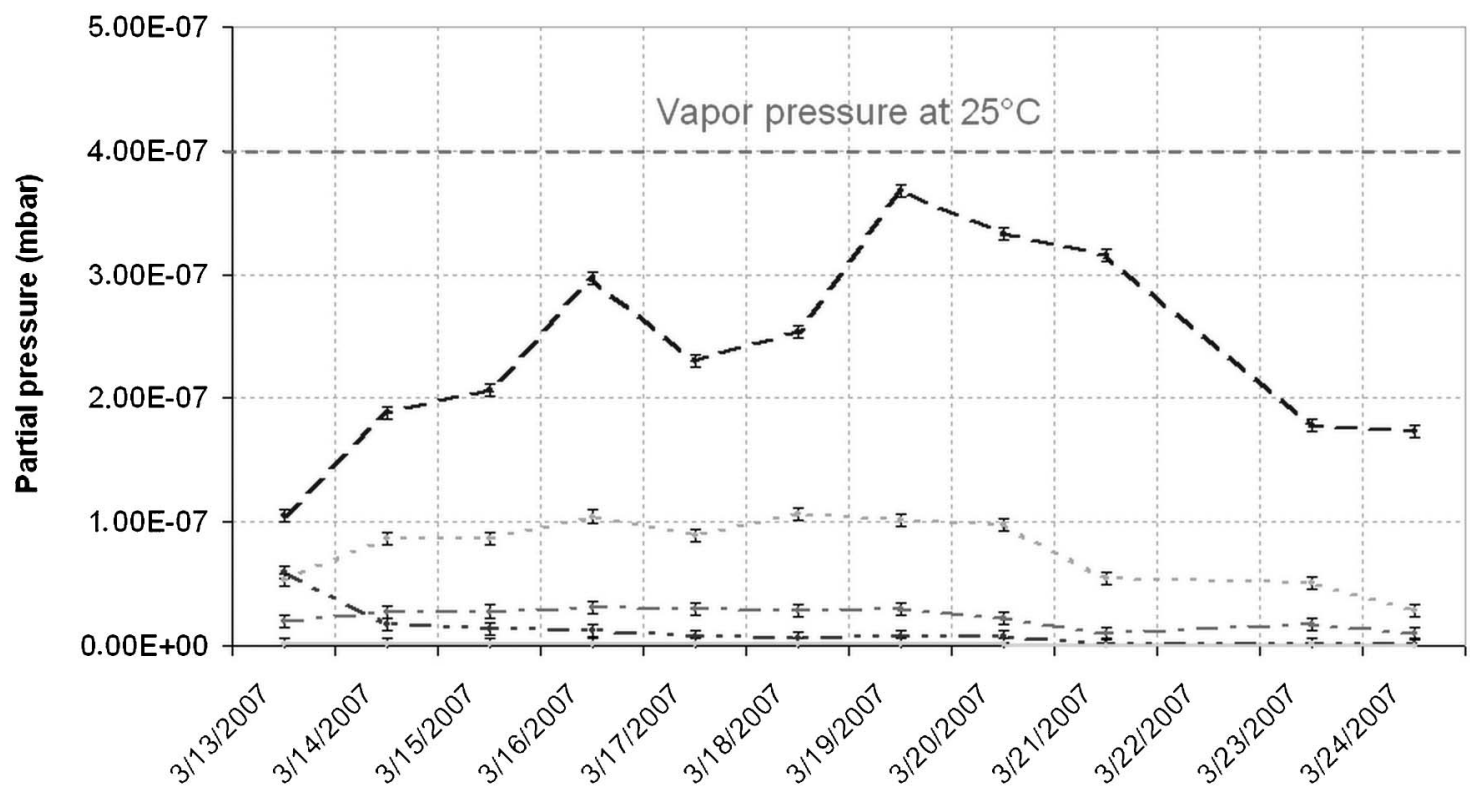

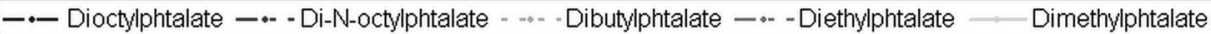

Fig. 1. Daily measures of phthalates in the FCS environment, and comparison of DOP measured partial pressure with vapor pressure. 
find few monolayers of this molecule on all optical surfaces. Also, as DOP is condensable and found in significant concentration in the LIL atmosphere, the risk of finding it under liquid form is not negligible. To study these two contamination modes, we deliberately contaminated fused silica samples with DOP in both gaseous and liquid phase, as described in Sections 2 and 3 respectively. In these sections, the two contamination modes are detailed, as are the different chemical and morphological contamination characterization of the surfaces. Results of the laser tests are then presented. In Section 4, we describe the means employed to explain the damages observed. We outline the importance of the morphology, and this leads us to suggest a laser induced damage mechanism. This hypothesis is supported by a model that is subsequently detailed. Finally, we offer our conclusion in the last section.

\section{Effect of Dioctylphthalate Contamination in Gaseous Phase on Laser Induced Damage of Fused Silica}

In this section, the gaseous phase contamination of fused silica optics with DOP is described. Gaseous phase contamination consists of exposing the optics in a confined atmosphere. To saturate the atmosphere with DOP $\left(\mathrm{C}_{24} \mathrm{H}_{38} \mathrm{O}_{4}, 117-81-7\right)$, the optic and $10 \mathrm{~mL}$ of liquid DOP are placed in a clean glass box, then heated up to $70^{\circ} \mathrm{C}$ in a drying oven during one hour and maintained a few minutes at $20^{\circ} \mathrm{C}$ in order to help produce condensation of organics on the surface of the sample. To avoid any external contamination and to guarantee the repeatability of the contamination process, the glass boxes are cleaned every time in a washing machine with L51 soap followed by an ethanol cleaning.

After gaseous phase contamination, GC-MS analysis with Clarus 500 Perkin-Elmer equipment is performed to identify the nature of the contaminants. GS-MS analysis starts with liquid extraction with a solvent composed of an iso-volume mix of acetone $\left(\mathrm{C}_{3} \mathrm{H}_{6} \mathrm{O}, 67-64-1\right)$ and chloroform $\left(\mathrm{CHCl}_{3}, 67-66-3\right)$ and ultrasound. The organic contamination on the substrates surface is consecutively sampled twice. The important experimental parameters are listed in Table 1. The initial oven temperature is set at $350^{\circ} \mathrm{C}$. Añalyses are made on a reference clean substrate and a contaminated one. The reference is heated up with the same experimental procedure as the contaminated substrate without any contaminant. The detection limit has been evaluated at $20 \mathrm{ng}$ per sample. After the contamination experience, we confirm the presence of DOP in substantial quantity compared to the reference optics. Table $\underline{2}$ shows that

Table 1. Experimental Parameters of Gas Chromatograph Coupled with Mass Spectrometer Analysis
Injection temperature

Chromatographic column

Mass scanning $350^{\circ} \mathrm{C}$

BPX5 $(25 \mathrm{~m} / 0.15 \mathrm{~mm} / 25 \mu \mathrm{m})$ $40-525 \mathrm{amu}$
Table 2. Estimated Surfacic Contamination

\begin{tabular}{lcc}
\hline Sample & $\begin{array}{c}\text { DOP } \\
\text { (ng/sample) }\end{array}$ \\
\hline Reference & Incubation $70^{\circ} \mathrm{C} 1 \mathrm{~h}$ & 401 \\
DOP contaminated & Incubation $70^{\circ} \mathrm{C} 1 \mathrm{~h}$ with DOP & 1300 \\
\hline
\end{tabular}

the quantity of DOP on the contaminated sample is more than 3 times higher than on the reference sample. The presence of DOP on the reference is not surprising as it is a usual contaminant of surfaces. $1300 \mathrm{ng}$ of DOP found on the contaminated sample corresponds to a thickness of about $3 \mathrm{~nm}$. For the morphology study of the deposit, atomic force microscopy (AFM) is used. Imaging was performed with a thermomicroscope autoprobe CR Research AFM. Silicon cantilevers with a force constant of about $40 \mathrm{~N} / \mathrm{m}$ were used with a silicon tip (NCL Nanosensor). All operations were carried out in air at room temperature inside a glove box under relative humidity of $20-25 \%$. Images were collected by the tapping mode and are presented in Fig. 2. Figure 2 compares the same area before and after contamination. Substantial contamination at the surface of a sample such as an oil film can cause AFM image artifacts [15]. Such artifacts appear as streaks on the images, especially in locations where there are sharp features and edges on the sample surface such as scratches or digs. It is exactly what we see in Fig. 2. Each of the specks in Fig. 2(a) correspond to streaks on the images after contamination in Fig. 2(b). Therefore the AFM observations show, on the surface of the optics, the presence of a film that is known to be mainly DOP as confirmed by GC-MS experiments as detailed previously. In summary, AFM and GC-MS experiments demonstrate the presence of a nanometric film of DOP adsorbed on the samples during gaseous contamination.

Our laser irradiation test uses a tripled neodymium doped yttrium aluminum garnet (Nd:YAG) laser at a wavelength of $355 \mathrm{~nm}$. The spatial beam profile is Gaussian with a $1 / e^{2}$ diameter of $600 \mu \mathrm{m}$. The pulse is a single mode longitudinally, with average pulse duration $\tau=2.5 \mathrm{~ns}, \tau$ being defined as the ratio of total energy to peak power. The laser scans the substrate, raster scan test procedure [16], with a step of $300 \mu \mathrm{m}$ in order to realize a complete irradiation of the defined component area. With a pulsed laser, spatial and temporal profiles as well as energy fluctuate from shot to shot. During the test, energy, spatial, and temporal profiles are recorded to calculate real fluence of each shot. Temporal profile is rather stable; the laser was checked to go on working with a single longitudinal mode. Then the observation of irradiated areas with a long focal length working microscope at normal incidence gives a damage map of the sample. The minimum damage size detected is about $10 \mu \mathrm{m}$ [16]. With this setup, a shot to shot correlation is performed between the damage occurrence and the corresponding real fluence. A damage site density is then plotted as a 


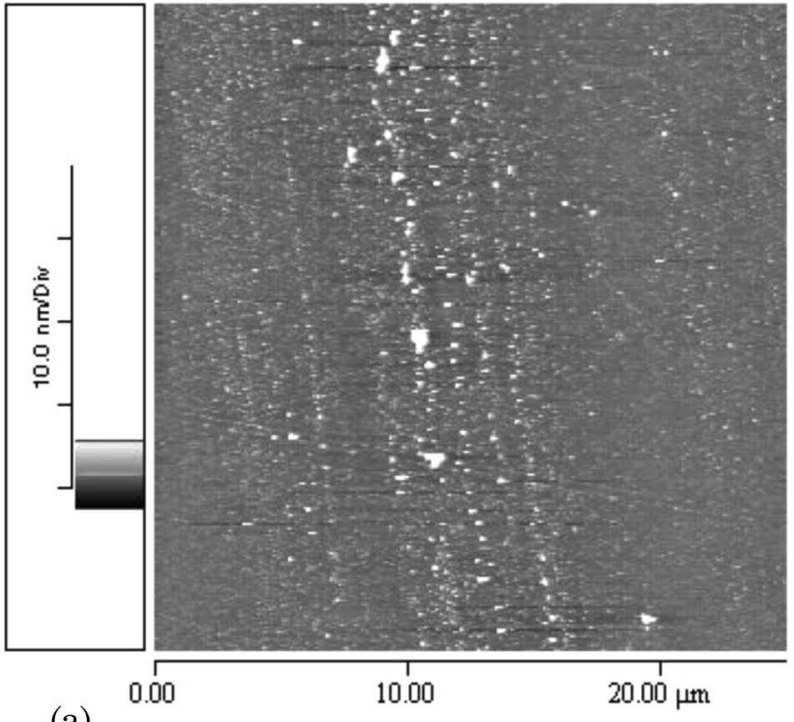

(a)

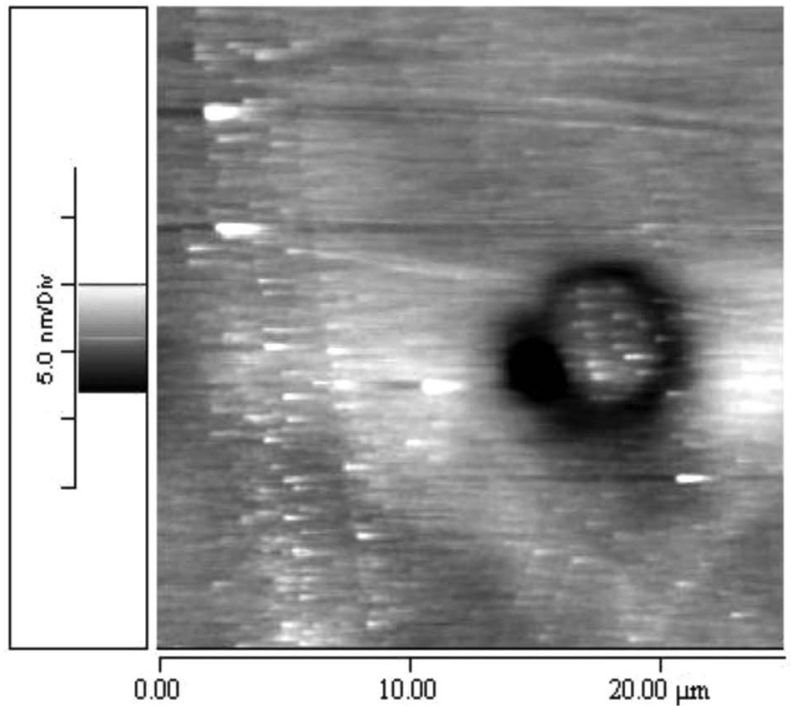

(b)

Fig. 2. AFM observation of a sample (a) before and (b) after DOP contamination in gaseous phase.

function of peak fluence. The irradiation tests performed on bare polished fused silica contaminated in gaseous phase presented in Fig. 3 show damage density for one of the reference samples. The laser tests have been repeated many times with the same result, so we conclude that a few monolayers of DOP obtained by gaseous contamination on bare polished fused silica optics have little effect on the laser induced damage density at $351 \mathrm{~nm}$. Next, liquid phase contamination is investigated since it seems to be possible to find DOP in liquid form in the LIL facility.

\section{Effect of Dioctylphthalate Contamination in Liquid Phase on Laser Induced Damage of Fused Silica}

The liquid phase contamination was made by spin coating using $0.5 \mathrm{ml}$ of DOP $\left(\mathrm{C}_{24} \mathrm{H}_{38} \mathrm{O}_{4}, 117-81-7\right)$. First, the sample reaches a speed of 600 revolutions per minute during 30 seconds when the droplet of

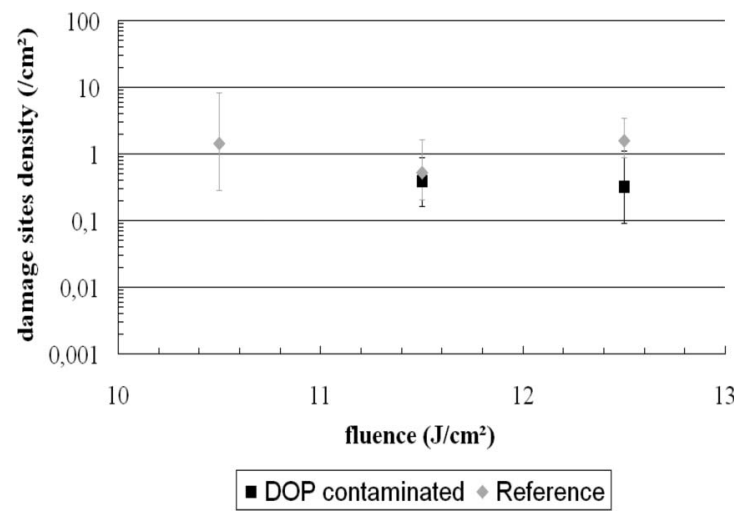

Fig. 3. Comparison of laser damage density between a reference sample and a sample contaminated by DOP in gaseous phase.

contaminant is set down; then the sample goes on turning at 1500 revolutions per minute during 60 seconds to spread out the liquid. Contaminated samples were observed by optical microscopy with a Leica DMLM equipped with a $20 \times$ objective lens in normal incidence. This observation revealed the presence of droplets from a few microns to a few hundred microns radially spread onto the optics. Droplets shapes were measured on a Lasertec 1LM21WD optical profilometer. This device uses a He-Ne laser beam $(633 \mathrm{~nm})$, normal to the surface to be observed, and for the $50 \times$ objective, the lateral and vertical resolutions are $300 \mathrm{~nm}$ and $100 \mathrm{~nm}$, respectively. A typical image of a droplet is shown in Fig. 4; the shape is close to a portion of sphere.

The contaminated samples were laser tested with a raster scan procedure [16]. Two configurations were tested where droplets were placed on the input or on the output surface as shown in Fig. 5 .

Figure 6 shows systematic damage under the droplets. The damage appeared for droplets larger than approximately $10 \mu \mathrm{m}$, at $1 \mathrm{~J} / \mathrm{cm}^{2}$ for the front surface irradiation configuration and $4 \mathrm{~J} / \mathrm{cm}^{2}$ for the output surface irradiation configuration. After liquid phase

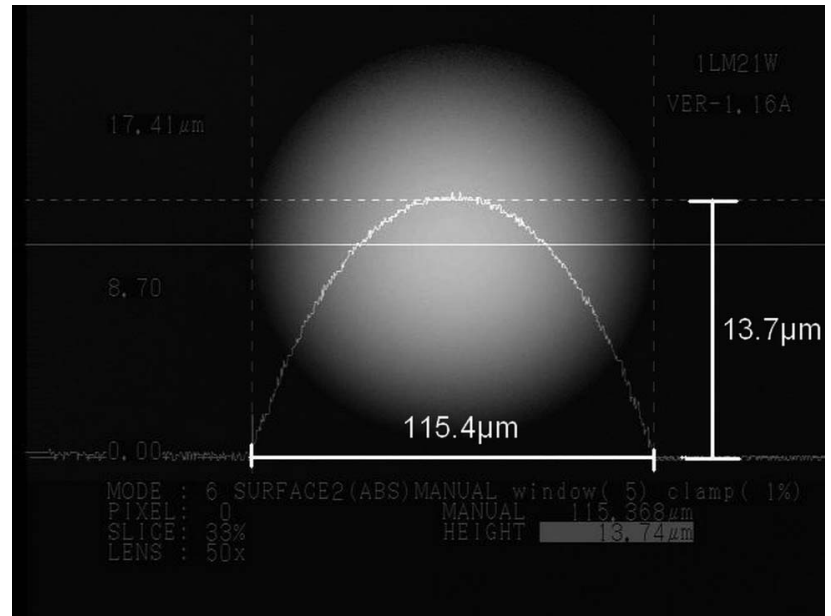

Fig. 4. Typical image of a DOP droplet on fused polished silica optics measured with a Lasertec 1LM21WD optical profilometer (top view and side view superposed- $x$ and $y$ scales are different). 


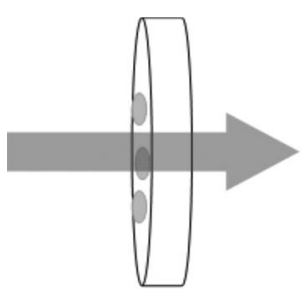

(a)

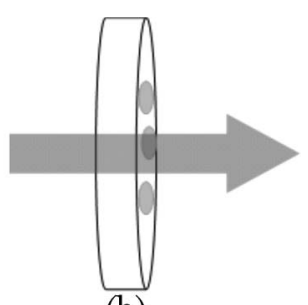

(b)
Fig. 5. Laser irradiation configurations: (a) droplets placed on input surface, (b) droplets placed on output surface.

contamination, laser damage density increases significantly for bare polished fused silica optics at $351 \mathrm{~nm}$. The peculiar morphology of the contaminant seems to be responsible of the laser induced damage degradation. The next section describes the complementary experiments we made to find out the damage mechanism.

\section{Discussion}

For samples contaminated by spin coating, droplets scattered on the surface generate systematic damage for droplets larger than a few microns, and for fluences lower than our typical LIL/LMJ fluence.

The damage sites are situated in the bulk of the samples and centered under the droplets. Because of the position of these damage sites, confocal microscopy was used to give an overview of both the droplet and the damage after irradiation. Confocal images are acquired on a Leica DMR TCS SP2 microscope at normal incidence. The following experimental conditions were used: $20 \times$ objective, $458 \mathrm{~nm}$ wavelength laser normal to the surface to be observed, lateral resolution of $280 \mathrm{~nm}$, and vertical resolution of $770 \mathrm{~nm}$. An example of such an acquisition is given in Fig. 7. Confocal microscopy gives the measurement of the damage depth. Nevertheless, for more simplicity and rapidity, damage depths were evaluated by optical microscopy with a Leica DMLM microscope. Vertical resolution of this microscope is

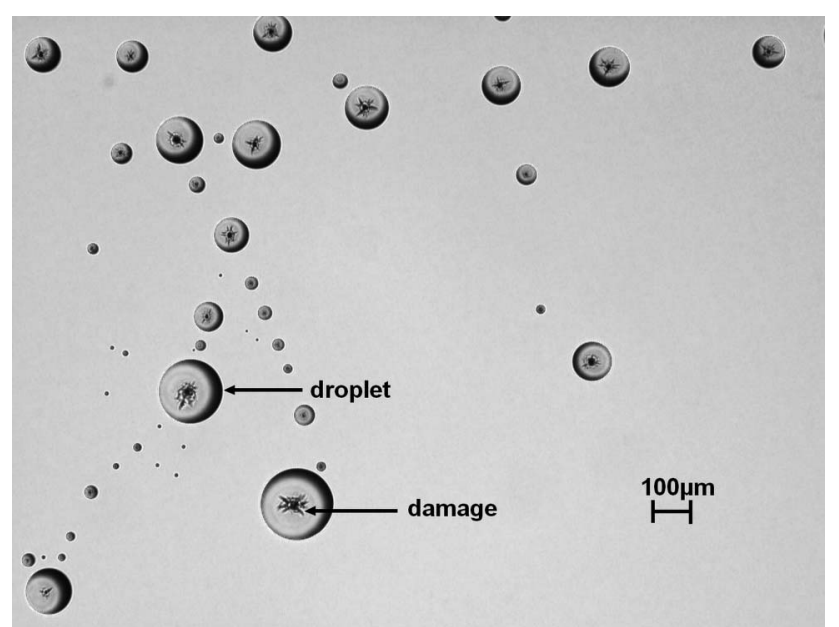

Fig. 6. Polished fused silica polluted by spin coating and raster scan irradiated with droplets on the output surface. A Leica DMLM optical microscope was used.

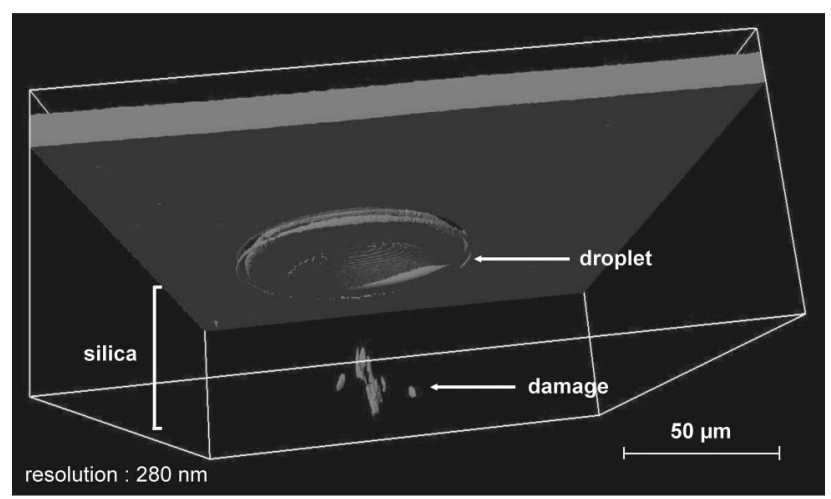

Fig. 7. Confocal microscopy image of a damage generated by droplet on silica.

about $1 \mu \mathrm{m}$. Measurements prove that damage depths depend on the size of the droplets and theirs position (input or output surface).

To evaluate the role of physical/chemical mechanisms [7-11] in the damage process, spectroscopic measures were completed. First, the absorption coefficient of DOP at a wavelength of $355 \mathrm{~nm}$ was measured. A value of $0.1 \mathrm{~cm}^{-1}$ was found. Considering a thermally isolated contaminant deposit of thickness $e$ with $e \alpha \ll 1$, the heating of the film $\Delta T$ during a single shot is given by

$$
\Delta T=\frac{\alpha F}{C_{p} \rho}
$$

where $\alpha$ is the film's absorption coefficient, $F$ is the fluence, $C_{p}$ is the film's specific heat, and $\rho$ is the film's density. In the case of DOP, the specific heat is $1800 \mathrm{~J} / \mathrm{kg} / \mathrm{K}$ and the density is $980 \mathrm{~kg} / \mathrm{m}^{3}$. For a pulse of $10 \mathrm{~J} / \mathrm{cm}^{2}$, the increase of temperature is about $0.06{ }^{\circ} \mathrm{C}$. This was too low to explain a material breakdown by an increase in temperature, and mechanical rupture due to rising temperature cannot explain the damage observed. Raman spectra of droplets before and after irradiation were made on a LabRam 1B microspectrometer from Jobin Yvon, coupled with a Ar-Kr Spectra Physics 2018 laser. The emission ray used was at $514.5 \mathrm{~nm}$, and detection was made with a CCD camera. In both cases, we measure the exact signature of DOP (see Fig. 8), and the identical traces show that a photo-induced chemical damage mechanism can be ruled out.

To get a better understanding of the damage process, some samples were slowly polished on a Logitech PM5 machine until the bulk damage came to the surface. Side and top views of a typical damage crater can be seen in Fig. 9. Damage craters were seen to consist of a solidified previously molten region surrounded by a near concentric region of fractured material as shown in Fig. 9(a). This damage morphology is in good concordance with results from Wong [17]. In order to identify the nature of the damaged material, x-ray photoelectron spectroscopy (XPS) analysis was done on a bulk damage site revealed by polishing and on an undamaged zone 


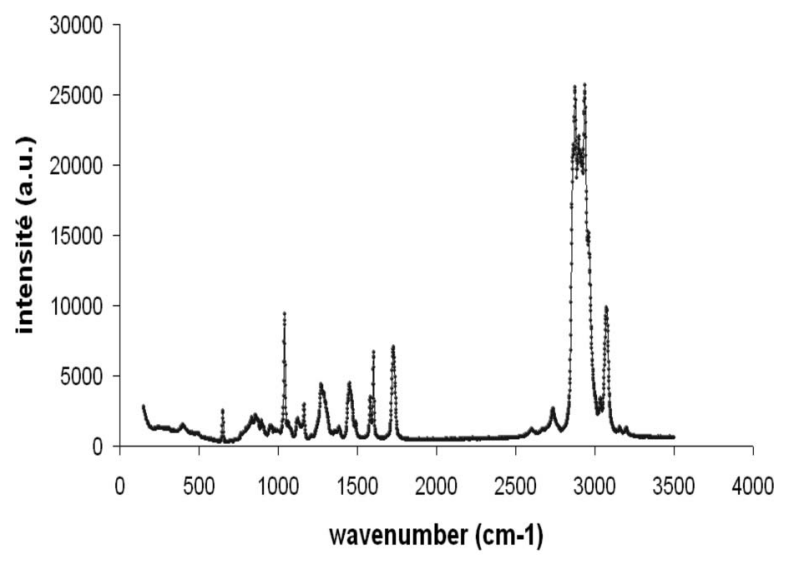

- before laser irradiation - after laser irradiation

Fig. 8. Raman spectrum of a liquid phase contamination sample before and after laser irradiation.

of a sample. The results are presented in Fig. 10. XPS spectra were acquired on a VG ESCALAB 220i-XL system. The $\mathrm{x}$-ray source was a $\mathrm{Mg}-\mathrm{K} \alpha$ beam $(1253.6 \mathrm{eV})$ with a power of $100 \mathrm{~W}$. The analyzed area was about $150 \mu \mathrm{m}$. On undamaged silica, we found a Si2p spectrum with a maximum at a binding energy of $103.5 \mathrm{eV}$ attributed to $\mathrm{Si}^{4+}$ bonding. The damage area also showed a Si2p spectrum with a maximum at $103.5 \mathrm{eV}$, but the fitting of this spectrum disclosed an additional component at lower energy (i.e., $101.7 \mathrm{eV}$ ) characteristic of lower valence $\mathrm{Si}^{3+}$ species [17]. A supplementary peak at $99.6 \mathrm{eV}$ assigned to $\overline{\mathrm{Si}^{0}}$ is particularly distinguishable on damage generated by droplets placed on the input surface. Wong [17] and Awazu [18] both noticed these silica modifications when silica was subjected to high laser fluences. Awazu [18] showed that reduction can continue until 0 degrees species on damaged silica. This shows that the high fluence is at the origin of the damage mechanism, and earlier showed that no thermic or photo-chemical effect could explain the damages observed.

Considering that the position of the damage site was always associated with a droplet, we suspected a droplet micro-lensing effect, inducing a local increase of power density. The damage morphology in Fig. 9(b) seems to be in accordance with this hypothesis as it takes the shape of the laser beam geometrical caustic. Droplets were considered to be spherical. Since DOP has a refractive index, $n$, close to the index of fused silica $(n=1.48$ at the wavelength $\lambda=351 \mathrm{~nm}$ ), we considered two cases associated with the two irradiation configurations presented in Fig. 5. Droplets on the input surface were taken as equivalent to spherical diopters with a transmission coefficient of $96 \%$. Droplets placed on output surfaces were considered as spherical mirrors with a reflection coefficient of $4 \%$. We calculated Fresnel diffraction by a circular aperture of the focused beam including the effects of aberration. This can be written in the following form in the Fresnel approximation:
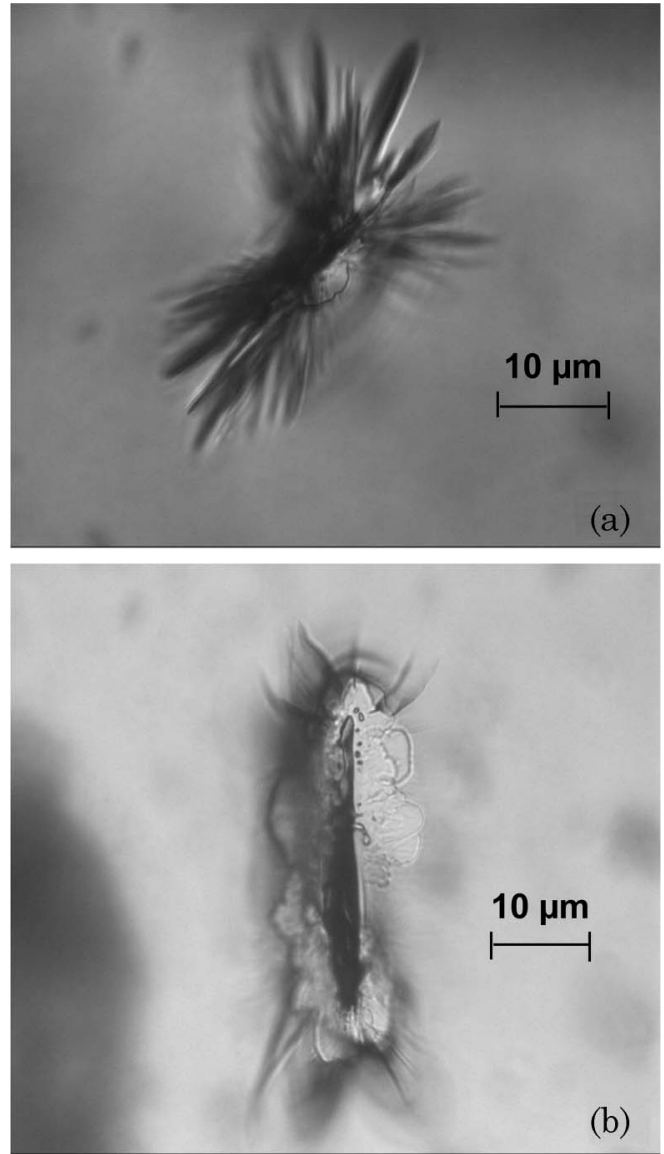

Fig. 9. Typical morphology of bulk damage after polishing: (a) top view, (b) side view.

$$
A(\rho)=-\frac{2 i k \pi}{z} e^{-i \frac{k \rho^{2}}{2 z}} \int_{0}^{R} A(r) e^{-i \Phi} e^{-i \frac{k r^{2}}{2 z}} J_{0}\left(\frac{k r \rho}{z}\right) r \mathrm{~d} r
$$

where $\rho$ and $r$ are cylindrical radial coordinates in the observation and aperture planes, respectively, $R$ is the droplet's radius, $z$ is the propagation axis, $k=2 \pi n / \lambda$ is the wave number, and $J_{0}$ is the zeroth order Bessel function. The phase difference $\Phi$ resulting from the contaminant droplets is then given by the following expression:

$$
\Phi=-k\left(\frac{r^{2}}{2 f}-\Delta\right)
$$

The focal distance is $f=n R_{c} /(n-1)$ for a spherical diopter and $f=R_{c} / 2$ for a spherical mirror, where $R_{c}$ is the radius of curvature of the droplet. $\Delta$ is the wave aberration of the system; the main ones, in our case, are defocus and spherical aberrations. We used ZEMAX optical software to describe the aberration parameters in terms of Zernike polynomials. With this analytical model, we calculated the beam fluence at the average damage depth measured by optical microscopy. An example of the calculated fluence distribution at one damage position is given in 


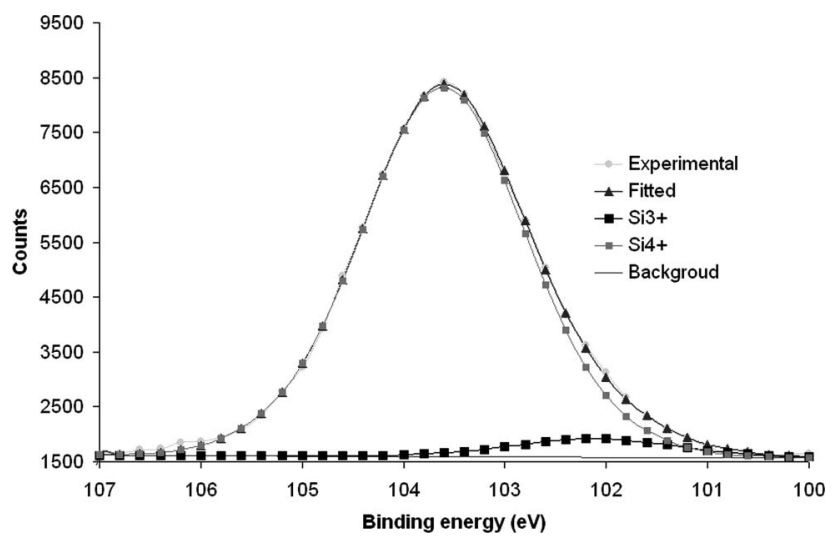

Fig. 10. Line profile of the Si2p photoemission peak on a damage site.

Fig. 11. Calculated maximum fluences are between $35 \mathrm{~J} / \mathrm{cm}^{2}$ and $100 \mathrm{~J} / \mathrm{cm}^{2}$ for all the damage sites positions and for both irradiation configurations. We compared these values with bulk $\mathrm{SiO}_{2}$ laser induced damage threshold data. Kuzuu [19] reported a laser damage threshold of $20 \mathrm{~J} / \mathrm{cm}^{2}$ at $355 \mathrm{~nm}$ and $0.85 \mathrm{~ns}$ on synthetic fused silica. This value is equivalent to $37 \mathrm{~J} / \mathrm{cm}^{2}$ at $2.5 \mathrm{~ns}$ using a $\tau^{0.5}$ scaling law [20]. Consequently, calculated maximum fluences are greater than the real bulk damage threshold measured in fused silica, demonstrating that the micro-lens focalization mechanism can explain the damage observed.

Previous results have been obtained on bare polished fused silica samples. Nevertheless, LIL/LMJ optical components have a solgel antireflecting coating [21] to reduce the transmission losses along the laser beam path. Therefore we also studied the effect of DOP on solgel coated fused silica polished samples to compare to our previous results on bare polished fused silica samples. In the case of solgel coated samples, gaseous contamination was carried out, and the results showed no effect like for bare silica samples. Also, the same droplet liquid contamination studies were done on solgel coated samples. Here, we also observed a different behavior, since, after a few minutes, the droplets partially spread into the porous

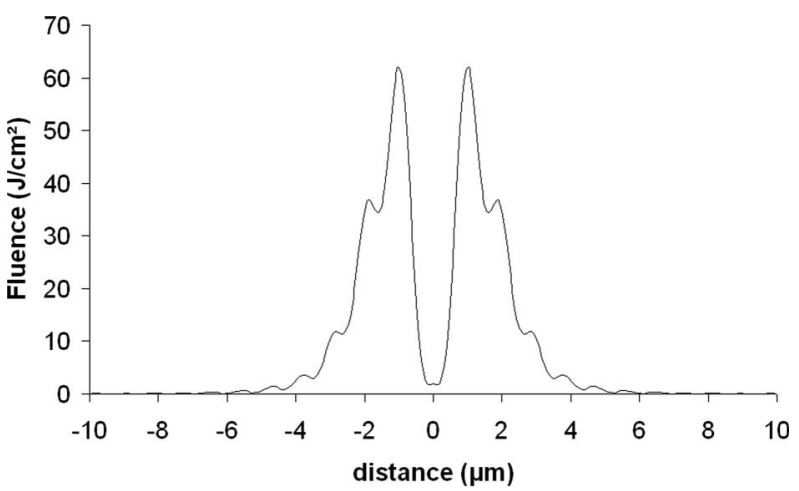

Fig. 11. Cross section of fluence profile of laser beam propagated after a $17.5 \mu \mathrm{m}$ radius and $3.3 \mu \mathrm{m}$ thick droplet with a paraxial focus of $150.6 \mu \mathrm{m}$ at the damage position $121.6 \mu \mathrm{m}$. solgel coating. On antireflecting coated silica samples, after a few days, the droplets spread into the porous solgel coating (which became whitish). The droplet's radii increase due to their spreading into the coating. An irradiation at $10 \mathrm{~J} / \mathrm{cm}^{2}$ did not generate any damage. Using the same model, we checked, and the local fluences stayed below the bulk damage threshold, as the shape of the droplets leads to a focalization distance larger than the substrate thickness. The solgel antireflecting coating thus protects the optics from this type of contamination damage.

\section{Conclusion}

We studied the effect of DOP organic contamination in gaseous and liquid phase on the laser induced damage density of polished fused silica optics at $351 \mathrm{~nm}$ in the nanosecond regime. We deliberately contaminated bare and solgel polished fused silica optics with DOP. In gaseous phase the reference samples as well as the contaminated ones showed the same damage behavior. On the contrary, we observed systematic damage of bare optics contaminated in liquid phase, for fluences lower than the usual damage threshold. This damage event was correlated with the presence of DOP droplets. Using optical calculations we demonstrated that the droplets play the role of micro-lenses. The resultant beam focusing creates a peak fluence and causes damage. However, knowing the widespread use of organic material in industrial environments, especially plasticizers like DOP, and the numerous demonstrations of damage events due to physical or chemical processes, it is important to highlight that the morphology of the contaminant deposit can also be responsible for the decrease of laser induced damage threshold of fused polished silica optics rather than purely physical or chemical processes.

The authors acknowledge the experimental support of M. Maglione and F. Guillen from Institut de Chimie de la Matière Condensée de Bordeaux (ICMBC) Laboratory, P. Legros from Plate-forme d'Imagerie Cellulaire Institut des Neurosciences (PICIN), and L. Lamaignère, T. Donval, and M. Loiseau from Commissariat a l'Energie Atomique (CEA) as well as the TERA Environment and Alphanov companies for the use of their equipment. The authors thank H. Bercegol, P. Grua, and C. Sauteret for valuable discussions.

\section{References}

1. M. L. André, "Status of the LMJ project," Proc. SPIE 3047, 3842 (1996).

2. B. M. Van Wonterghem, S. C. Burkhart, C. A. Haynam, K. R. Manes, C. D. Marshall, J. E. Murray, M. L. Spaeth, D. R. Speck, S. B. Sutton, and P. J. Wegner, "National Ignition Facility commissioning and performance," Proc. SPIE 5341, 55-65 (2004).

3. N. A. Fleurot, A. Adolf, M. Andre, J. L. Bruneau, C. Cavailler, M. Novaro, P. Philippe, F. Kovacs, B. Le Garrec, J. M. Di Nicola, and J. P. Leidinger, "The Ligne d'Integration Laser 
(LIL): construction status and first 1-w light early results," Proc. SPIE 4948, 418-424 (2003).

4. H. Bercegol, A. Boscheron, J.-M. Di-Nicola, E. Journot, L. Lamaignère, J. Néauport, and G. Razé, "Laser damage phenomena relevant to the design and operation of an ICF laser driver,” J. Phys. Conf. Ser. 112, 032013 (2008).

5. R. Chow, R. Bickel, and J. Ertel, "Cleanliness validation of NIF small optics," Proc. SPIE 4774, 19-24 (2002).

6. R. R. Kunz and V. Libermann, "Experimentation and modelling of organic photocontamination on lithographic optics," J. Vac. Sci. Technol. B 18, 1306-1313 (2000).

7. A. E. Duisterwinkel and A. T. G. M. Bastein, "Feasibility of UV cleaning of $157 \mathrm{~nm}$ reticles," Microelectron. Eng. 67-68, 39 (2003).

8. F. E. Hovis, B. A. Shepherd, C. T. Radcliffe, and H. A. Maliborski, "Contamination damage in pulsed $1 \mu \mathrm{m}$ lasers," Proc SPIE 2714, 707-716 (1996).

9. C. Scurlock, "A phenomenological study of contamination enhanced laser induced damage in sealed lasers," Proc. SPIE 5647, 86-91 (2004).

10. C. Y. Sheng, "Effect of laser-induced damage on optical windows in the presence of adhesives under simulated thermal-vacuum conditions," Proc. SPIE 6403, 1-12 (2007).

11. L. Bruel, "Environmental effects on optical component aging," Proc. SPIE 4932, 158-169 (2003).

12. I. Tovena-Pecault, K. Bien-Aime, and A. Pereira, "Organic molecular contamination in prototype of the future Laser MegaJoule," presented at Pharmatech, Cork, Ireland, 16-18 September 2008.

13. D. M. Price, "Vapor pressure determination by thermogravimetry," Thermochim. Acta 367-368, 253-262 (2001).
14. A. Pereira, J.-G. Coutard, S. Becker, I. Tovena, P. Bouchut, and G. Ravel, "Impact of organics contamination on $1064 \mathrm{~nm}$ laser induced damage threshold of dielectric mirrors," Proc SPIE 6403, 6403-0I-1 (2006).

15. P. West and N. Starostina, "AFM image artefacts" (LOT-Oriel Gruppe Europa).

16. L. Lamaignère, S. Bouillet, R. Courchinoux, T. Donval, M. Josse, J.-C. Poncetta, and H. Bercegol, "An accurate, repeatable, and well characterized measurement of laser damage density of optical materials," Rev. Sci. Instrum. 78, 103105 (2007).

17. Joe Wong, J. L. Ferriera, E. F. Lindsey, D. L. Haupt, D. Hutcheon, and J. H. Kinney, "Morphology and microstructure in fused silica induced by high fluence ultraviolet $3 \pm w$ $(355 \mathrm{~nm})$ laser pulses," J. Non-Cryst. Solids 352, 255-272 (2006).

18. K. Awazu, "Ablation and compaction of amorphous $\mathrm{SiO} 2$ irradiated with ArF excimer laser," J. Non-Cryst. Solids 337, 241-253 (2004).

19. N. Kuzuu, K. Yoshida, H. Yoshida, T. Kamimura, and N. Kamisugi, "Laser-induced bulk damage in various types of vitreous silica at $1064,532,355$, and $266 \mathrm{~nm}$ : evidence of different damage mechanisms between $266 \mathrm{~nm}$ and longer wavelengths," Appl. Opt. 38, 2510-2515 (1999).

20. B. C. Stuart, M. D. Feit, and A. M. Rubenchik, "Laser-induced damage in dielectrics with nanosecond to subpicosecond pulses," Phys. Rev. Lett. 74, 2248 (1995).

21. H. G. Floch, P. F. Belleville, P. M. Pegon, C. S. Dijonneau, and J. R. Guerain, "Sol gel optical thin films for an advanced megajoule-class Nd:glass-laser ICF driver," Proc. SPIE 2714, 521-536 (1996). 